\title{
Improvement of Continuous Lateral Surface Mining Method for Coal Extraction from Closed Mines' Pillars
}

\author{
Alexey SELYUKOV ${ }^{1}$, Sergey ZHIRONKIN ${ }^{2} *$ and Michal CEHLÁ $\boldsymbol{R}^{3}$
}

Authors' affiliations and addresses:

${ }^{1}$ T.F. Gorbachev Kuzbass State Technical University, 650000 28Vesennyast., Kemerovo, Russia

e-mail: sav.ormpi@kuzstu.ru

${ }^{2}$ Siberian Federal University, Institute of Trade and Economy, 66004179 Svobodny av.,

Krasnoyarsk, Russia

e-mail: szhironkin@sfu-kras.ru

T.F. Gorbachev Kuzbass State Technical

University, 650000 28Vesennyast., Kemerovo, Russia

e-mail: zhironkinsa@kuzstu.ru

National Research Tomsk Polytechnic University, 63405030 Leninast., Tomsk, Russia

e-mail: zhironkin@tpu.ru

${ }^{3}$ Technical university of Košice, 04200 Letná 9 , Košice, Slovakia

e-mail: michal.cehlar@tuke.sk

*Correspondence:

Sergey Zhironkin, T.F. Gorbachev Kuzbass State Technical University, 650000 28Vesennyast.,

Kemerovo, Russia

e-mail: zhironkinsa@kuzstu.ru

How to cite this article:

Selyukov, A., Zhironkin, S. and Cehlár, M.

(2020). Improvement of Continuous Lateral

Surface Mining Method for Coal Extraction from

Closed Mines' Pillars. Acta Montanistica

Slovaca, Volume 25 (4), 542-562

DOI:

https://doi.org/10.46544/AMS.v25i4.09

\begin{abstract}
The presented paper deals with a continuous lateral method of closed mines' coal pillars surface mining and its advantages in land intensity, dust emissions, maximizing coal extraction, and overburden transporting costs. While inclined and steep coal seam strata in the pillars are widely exploited with land-and-cost intensive deepening longitudinal mining method, this article substantiates the choice of modification of block-and-layer continuous lateral mining method for different kinds of coal deposits. The aim of the study is to specify the modifications of the method proposed, define the stages of their carrying out, and emphasize the advantages over deepening longitudinal method of coal pillars surface mining. The basic principle of the proposed continuous lateral method of mining the coal pillars is limiting the final depth of quarry by the vertical height of the first floor of the underground mine workings. The continuous lateral mining method is detailed in the article in three modifications (for development coal seams strata of high and medium thickness, as well as distanced separate coal seams), which advantages are low land intensity and dust emission from the dump. Attention is also paid to the economic benefits of the block-andlayer continuous lateral method of mining coal pillars of closed mines, whereby the overburden transporting costs can be significantly reduced, while limitations of the proposed mining method concern specific sites of closed mines that make up a small part of the coal pillars extracted by surface mining today.
\end{abstract}

\section{Keywords}

coal pillars, surface mining, lateral mining method, direct dumping, land saving 


\section{Introduction}

Today, the global need for coal mining development is due to the growth of global electricity consumption and the demand for cheap, highly efficient, and easily transported energy sources. In turn, the global coal industry development's strategic objectives are the complete extraction of coal and the reduction of environmental damage caused by mining. The development of surface coal mining technologies contributes to the first problem's solution but hinders the second one, which is no less important - the greening of the mining.

An important step in the transition to a comprehensive achieving these strategic objectives is the complete extraction of coal from the pillars of closed mines, which reserves have already been depleted, using surface mining. (Manová et al., 2018), (Jarvie-Eggart, 2015) connects the need for this with the presence of significant volumes of coal in the pillars in the near-surface zone (first "floor") of the mine field, including the most valuable grades, which economically justifies their surface mining.

(Yang et al., 2016), (Sun et al., 2018) determine the need for the complete extraction of coal from mine pillars by the importance of avoiding endogenous fires and the exit of combustion products and methane to the surface, as well as preventing dips and surface subsiding.

At the same time, one can observe a lack of consensus on the most effective way to extract coal from coal mines' pillars $\neg-$ surface or underground. (Song et al., 2010), (Yu et al., 2018), (Zi and Ding, 2010) give arguments in favor of an underground method for coal pillars mining in existing mines in the course of improving coal extraction technologies and filling up the worked out space.

(Kushwaha et al., 2010), (US EPA, 2008), (Writer, 2014), (Hudeček and Stoniš, 2010 )consider using new means of drilling for underground mining of coal pillars. Lukhele, 2012)(Stoniš and Hudeček, 2009) offer auger machines using for this purpose.

It should be noted that, despite a number of advantages (the absence of surface disturbance, the obligatory filling of underground mine workings with inert materials), the underground method for extracting coal from mine pillars has one significant drawback - it is applicable only to existing mines. At the same time, in coal clusters with a high concentration of underground and surface mining, there is a certain share of mines closed for economic and production reasons (mainly a depletion of reserves). The only way to develop coal pillars for such sites is the use of surface mining.

Surface mining of coal in the pillars is mainly associated with open pits of small and medium annual capacity (up to 1 million tons), which develops the valuable grades of coal (U.S. Congress, Office of Technology Assessment, 1986), (Kurekhin, 2015). At the same time, continuous lateral mining method with filling the internal dump is recommended for low-dipping strata, deepening longitudinal method - for development of pillars in inclined and steeply dipping seams, with a constant expansion of the quarry field and placing of overburden in the external dump (Squillace, 1990), (Baruya, 2012), (Harper, 1985). This has an extremely negative impact on the environment in areas with a high concentration of mining operations, the surface of which turns into a "lunar" landscape, with closely spaced quarry fields and multi-tier external dumps.

On the whole, regarding the use of the continuous lateral mining method, the prevailing opinion is that it is intended for mining suites of horizontal and low-dipping coal seams (0-300) (Mitra and Saydam, 2012), (Kose et al., 2010), (Kennedy, 2009, since its main feature is the finite quarry depth equal to the stratification depth of the strata, especially of a high thickness (Zhengaoet al, 2017), (Mishra and Mohanty,2019).

Similarly, (Tatiya, 2014), (Czaplicki, 2010) consider the use of direct dumping with overburden transfer by draglines acceptable for low-dipping strata or as an alternative to overburden transportation by dump trucks, cars, or conveyors, but without taking into account the parameters of the mining method and the final parameters of the quarry.

In general, the use of the deepening longitudinal surface mining method is dictated, first of all, by the desire to extract coal from inclined and steeply dipping seams to the maximum possible depth (Changsheng, 2012). With regard to the extraction of coal from pillars of closed mines, this makes sense with consistently high coal prices on the one hand and a low concentration of surface mining in the region. On the contrary, in conditions of unstable coal prices and the presence of closely located quarry fields and dumps, it is advisable to use a continuous lateral mining method for coal extracting from pillars, with overburden moving to the internal dump with draglines, with a reduction in occupied land and dust emissions.

Along with indisputable advantages of surface coal mining, such as the lowest losses and the level of fatal accidents, the highest specific power of mining equipment, one cannot fail to note its main drawback - a high level of land intensity. Often, the development of surface coal mining in the region leads to the withdrawal of significant areas of land from agricultural circulation, to the growth of water and air pollution by dust, products of the combustion of explosives, and spontaneous combustion of coal in large areas (Litvin et al., 2017). At the same time, in the clusters with intensive coal mining, such as Kuzbass (Western Siberia, Russia), the urgent issue is the extraction of coal of valuable grades left underground in the pillars of closed mines, the volume of which in Kuzbass reaches tens of millions of tons (Oparinet al, 2012). It is possible to ensure the complete extraction of these "lost" reserves using modern methods of surface mining. 
The object of the pillars' surface mining is worked out upper levels of underground mine fields, which, especially on old Kuzbass mines built in the 1940 and operated until the 1990s, were developed with heavy losses (about 50-60\% of the reserves within the mine allotments (Kulakov, 1995). The remaining coal reserves at these levels of mines begin to ignite spontaneously, creating a dangerous ecological situation. In addition, a landscape unsuitable for urban development is created, characterized by dips, cracks, and subsidence.

Currently, many Kuzbass mines have surface mining sites within their allotments. However, these quarries and the used technology with transportation of overburden by dump trucks to external dumps do not meet environmental requirements. There are no scientific recommendations on the technology of quarrying in hazardous areas of mine fields, as well as there is no justification of the boundary contours of open-pit workings (Katsubin and Makridin, 2018). A characteristic feature of dead mines' fields is the disturbance of the rock array and the absence of concentrated coal reserves within their boundaries.

The actual state of mining operations and design decisions on coal surface mines in Kuzbass indicate that managing the technogenic resource of closed is implemented in isolated cases (Kuznetsovet al, 1997), (Cheskidov et al., 2014), (Lesin et al., 2015), so the coal pillars as a source of coal of valuable grades remain unmined. In addition, from the standpoint of the validity of the decisions made, they are often based on obsolete regulatory documents that lead to insufficient environmental efficiency, and therefore there is no complete implementation of them in the practice of coal surface mining (Tyulenev et al., 2018). This catastrophically aggravates the prospects for sustainable development of regions with concentrated coal mining as coal-producing increases.

It should be emphasized that the well-known technological solutions for surface coal mining consider creating new quarries in areas where there was no mining before (Bereznyak et al., 1970), (Hummel, 2012). Internal dumping, as an element of land preservation, has not been generally considered to date in the study of surface mining technologies for the development of the first floor of closed coal mines (with the exception of some works (Tyulenev et al., 2018), (Prakash et al., 2013). This is a limiting factor in the introduction of landsaving technologies, both in surface mining design and production.

In this regard, a comprehensive justification of development options for resource-saving surface mining technologies focused on the rational dumping of overburden in relation to existing quarry fields, including dead mine fields, developed by surface mining, as well as promising deposits, should be considered relevant. It is important to remember that the presence of underground workings and the movement of rocks above them complicates the conduct of surface mining, as it becomes necessary to ensure the stability of the slopes and sides of the quarry (Tanainoand Cheskidov, 1999), (Gvozdkova et al., 2017).

According to its characteristics, mine pillars containing coal reserves, suitable for surface mining can be divided into the following groups (Zhaoxueand Hong, 2010):

According to its characteristics, mine pillars containing coal reserves, suitable for surface mining can be divided into the following groups (Zhaoxue and Hong, 2010):

- pillars under the shaft inset;

- pillars under skip, rock-and-coal, and stand shafts;

- pillars for transport and energy communications;

- pillars for buildings and structures.

An example of a pillar within the boundaries of a mine field is a safety pillar under an industrial site formed by a coal seam with a thickness of more than $7 \mathrm{~m}$ (Fig. 1).

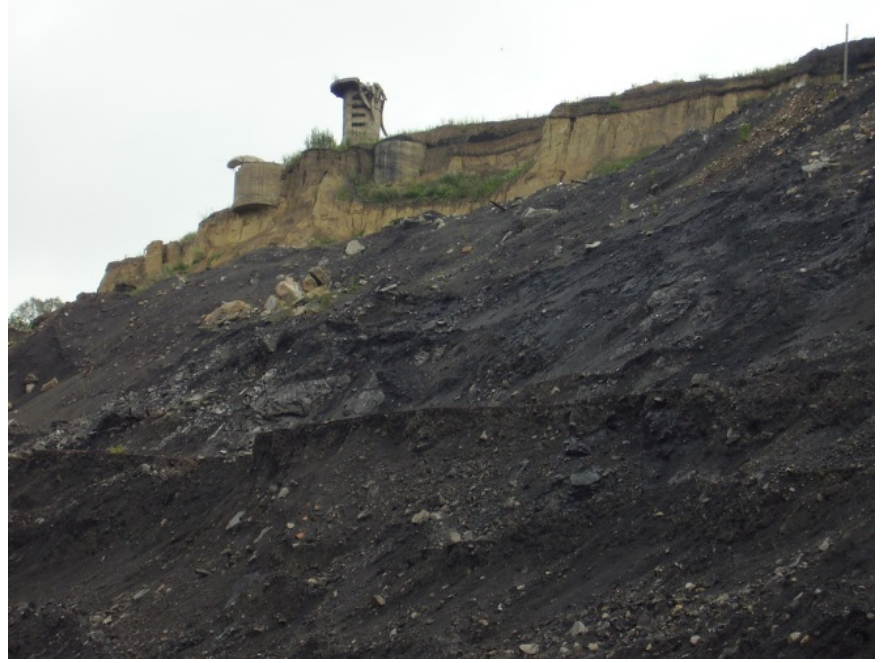

Fig. 1. The safety pillar under the industrial site of the Northern Maganak mine, Kuzbass 
The main reasons for leaving safety pillars in Kuzbass are the protection of residential settlements, industrial buildings and structures, permanent underground working and natural objects (60.3\% of all pillars), presence of areas with extinguished and existing endogenous coal combustion (38.1\%), as well as areas hazardous for breakthroughs of clay into existing workings and areas of geological faults (1.6\%) (Nazarov, 2011), (Zhironkin and Janocko, 2019).

After the development of the deposits by underground mining, the surface above them is a hazardous zone, characterized by dips, cracks, and faults, which contribute to the occurrence of fires from spontaneous combustion of the remaining coal reserves in pillars. The possibility of poisonous gases permeating the atmosphere through cracks and faults from the lower levels of mines is not ruled out.

On the Kuzbass surface mines extracting the coal from the pillars of closed mines, a deepening longitudinal mining method is used, which adds the problem of land disturbance and dust emission from external dumps.

To eliminate these problems, there is a need for surface mining with the extraction of the coal reserves remaining in pillars using technology with internal dumping and reclamation following the advancement of the working front. In this case, a reliable sealing layer of loose rocks is created over internal dumps, which protects the environment from the negative impact of dead mines.

The vertical height of the first floor from 80 to $130 \mathrm{~m}$ (in some cases - $180 \mathrm{~m}$ ) adopted at Kuzbass underground mines determines the depth of the surface mining site. The length of the quarry field is determined on the basis of distancing surface mining from the location of housing or other facilities. In general, the quarry field's length in connection with the above does not exceed 500-800 m, but in some cases reaches $4000 \mathrm{~m}$.

\section{Materials and Methods}

The research area concerns coal extracting from closed mines' pillars formed in a place of inclined and steeply dipping coal seams with small tectonic disturbances and total strata thickness of 100-800 m. The first floor of the closed mine's field must be high enough to contain the quarry $(60-180 \mathrm{~m})$.

The study aims to improve the continuous lateral surface mining method to make it applicable for coal extracting from mine's pillars with minimal environmental damage and in different conditions.

To determine the parameters of the working and dump zones of the quarry for continuous lateral mining method, the mining-and-geometric analysis was used, which allows determining the parameters of surface mining workings and the entire quarry based on linear and angular parameters of the deposit, operating parameters of the equipment and options for its installation.

Based on environmental requirements, the layered lateral continuous mining method with the development of a layer using direct dumping is the most appropriate for surface mining conditions in the fields of dead mines. The essence of this technology is as follows.

In one of the ends of the mine field across the strike of the coal seams strata, a preparatory trench is being constructed with a depth that ensures the horizontal layer's development using direct dumping (Fig. 2).

The mining of the rock-and-coal layer is carried out by subbenches in descending order with the excavation of the remaining reserves from the coal seams by hydraulic backhoes and excavation of the overburden by dragline into the internal dump.

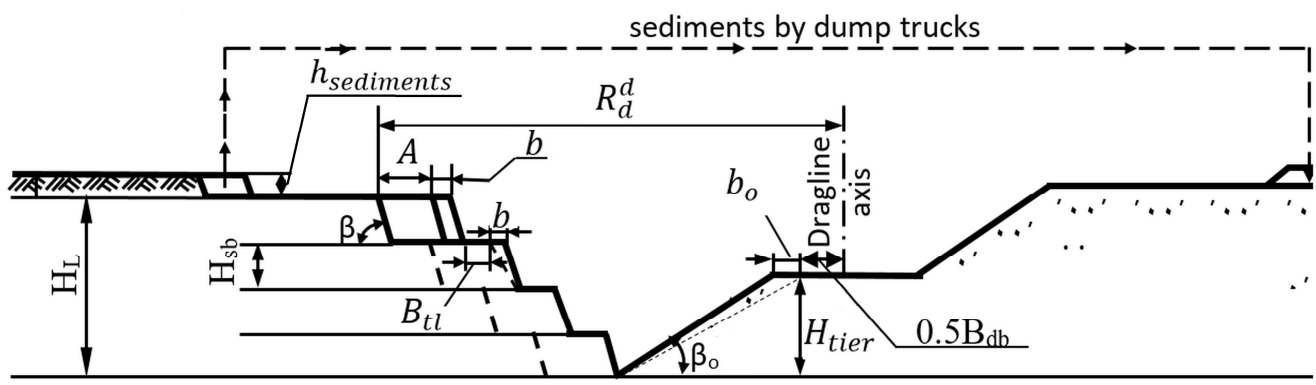

Fig. 2. The scheme for calculating the thickness of the excavated layer for direct dumping

Sediments are removed by a shovel with transportation by dump trucks to the surface of internal dump from hard rock formed by dragline using direct dumping.

The condition for the possibility of the development of a rock-and-coal layer with a thickness of $H_{l}$ by direct dumping is expressed by the equality of dragline's digging radius $R_{d}^{d}$ and the width of the working zone for mining the rock-and-coal layer $W Z W(1)$. The authors compiled equation (1) by modifying the equations for determining the parameters of the working and dump zones of the quarry when developing flat and low-dipping coal seams strata using direct dumping technology, as part of the continuous lateral mining method (Tyulenev et al., 2018), (Gvozdkova et al., 2017), (Nazarov, 2011): 


$$
W Z W=n \times\left[H_{s b} \cdot \operatorname{ctg} \beta+B_{e}+B_{t l}+b\right]-\left(B_{e}+B_{t l}+b\right)+A+H_{d i} \cdot \operatorname{ctg} \beta_{0}+b_{0}+0.5 B_{d b}(1)
$$

where:

$W Z W$ - width of the working zone, $\mathrm{m}$;

$n$ - number of developed subbenches;

$H_{s b}$ - subbench height, m;

$B_{e}-$ exit width, m;

$B_{t l}-$ width of a transport lane for through passage of dump trucks, m;

$\beta$ - angle of temporary standing of a slope, degrees;

$b$ - width of safety berm on the subbench, m:

$$
b=H_{s b}\left(\operatorname{ctg} \beta_{s b}-\operatorname{ctg} \beta\right)
$$

where: $\beta_{s b}$ - angle of steady slope of a bench, degrees;

$A$ - width of the stope of hydraulic backhoe for the extraction of coal seams (pillars), m;

$H_{d i}$ - installation height of a dragline in a dump zone, m;

$\beta o$ - natural angle of dump slope, degrees;

$b_{o}$ - safety berm at the dump site of the dragline installation, m:

$$
b_{o}=H_{d i}\left(\operatorname{ctg} \beta_{s d}-\operatorname{ctg} \beta_{o}\right)
$$

$\beta_{s d}$ - angle of a steady slope of a dump, degrees;

$B_{d b}$ - width of a dragline's base, $\mathrm{m}$.

$H_{\text {tier }}$ - the height of the internal dump tier, equals dragline's digging depth or (in some cases) the layer thickness $\left(H_{l}\right)$.

The permissible thickness of the rock-and-coal layer containing mine pillars, and developed by direct dumping $\left(H_{l}\right)$, is defined as:

$$
H_{l}=n \times H_{s b}
$$

or, taking into account the Eq. (1):

$$
H_{l}=\frac{R_{d}^{d}+B_{e}+B_{t l}+b-A-\left(H_{d l} \times c t g \beta+b_{o}+0.5 B_{d b}\right)}{H_{s b} \times c t g \beta+B_{e}+B_{t l}+b} \times H_{s b}
$$

Direct dumping technology for the extraction of coal from the pillars of closed mines involves the continuous mining of the upper layers of mine fields with the simultaneous extraction of the remaining coal reserves from the seams processed by underground mining. This technology is most preferred when coal mine fields are highly saturated.

For the low coal saturation of mine fields, simple conditions of coal seams occurrence, and significant thicknesses of rock interbeds, we consider it appropriate to use technology with a partial extraction of coal from the pillars only in areas of separately occurring coal seams. To do this, in one of the ends of the mine field across the outstretch of the coal seams, a preparatory lateral trench is carried out to a depth equal to the thickness of the sediments with the dumping the rock along one end side. Thus, coal seams under sediments are being stripped.

After that, longitudinal trenches pass from the lateral preparatory trench over the seams' exits under the sediments to a depth equal to the sediment's thickness, followed by excavation of the remaining coal reserves using hydraulic backhoes.

Following the excavation of coal seams, trenches are filled with sediments from their sides, followed by reclamation.

The proposed technology will protect the environment from the influence of pollutants caused by the incomplete mining of coal reserves within mine fields' boundaries, with simultaneous additional coal mining. After the technological and biological stages of land reclamation, the surfaces of internal dumps can be used for agricultural purposes.

The procedure for surface mining with the continuous mining of coal pillars is as follows. After the construction of the preparatory trench to the design depth, the development (in fact, completion) of the remaining coal reserves begins. For this, first of all, the advanced excavation of the fertile and potentially fertile layers of soil and sediments is carried out with separate storage on the side of the preparatory trench.

The technological parameters of the preparatory trench include the following. 
The width of the bottom of the preparatory trench $(\mathrm{Btb})$ is determined by the expression:

$$
B_{t}^{b}=0.5 B_{d b}+R_{b}+c+Z_{o}
$$

where:

$B_{d b}$ - width of a dragline's base, m.

$R_{b}$ - radius of rotation of the body of a dragline, $\mathrm{m}$;

$c$ - safety clearance between the body of the excavator and the side of the trench, $\mathrm{m}$ (minimum $c=1 \mathrm{~m}$ );

$Z_{o}$ - safety berm at the dragline installation site for the preparatory trench, $\mathrm{m}$ :

$$
Z_{o}=H_{d i}\left(\operatorname{ctg} \beta_{o}-\operatorname{ctg} \gamma_{p}\right)
$$

where:

$H_{d i}$ - installation height of a dragline in a dump zone, m;

$\beta o$ - natural angle of dump slope, degrees;

$\gamma_{f}-$ the angle of finalization of the side of the preparatory trench, degrees.

The width of the preparatory trench on top $\left(B_{t}^{t}\right)$ is determined by the expression:

$$
B_{t}^{t}=H_{t}\left(\operatorname{ctg} \gamma_{w}+\operatorname{ctg} \gamma_{f}\right)+B_{t}^{b}
$$

where:

$H_{t}$ - the depth of a preparatory trench (equals dragline's digging depth or (in some cases) the layer thickness), m; $\gamma_{\mathrm{w}}$ - slope angle of the working side of the preparatory trench, degrees:

$$
\gamma_{w}=\operatorname{arctg}\left(\frac{h_{b} \times \operatorname{ctg} \beta_{b}+(n-1) \times B_{b}}{H_{t}}\right)
$$

where:

$h_{b}-$ bench height in the worked-out layer, m;

$n$ - the number of worked steps in the layer;

$\beta_{b}$ - bench angle, degrees;

$B_{b}-$ width of transport berm, m

$$
B_{b}=B_{e}+B_{t l}+z
$$

where:

$B_{e}-$ width of the bulk exit, m;

$B_{t l}-$ width of a transport lane for through passage of dump trucks, m;

$z$ - safety berm width, $\mathrm{m}$ :

$$
z=h_{b}\left(\operatorname{ctg} \beta_{s d}+\operatorname{ctg} \beta\right)
$$

where:

$\beta_{s d}$ - angle of a steady slope of a dump, degrees;

$\beta$ - angle of temporary standing of a slope, degrees.

With a dead-end traffic pattern of the dump truck, the width of the transport berm $\left(B_{t r}{ }^{d e}\right)$ decreases by the width of the transport lane when driving through the truck:

$$
B_{t r}^{d e}=B_{e}+z
$$

The width of the working platform on the subbench $\left(W P_{s b}\right)$ :

$$
W P_{s b}=A+B_{t r}^{d e}
$$

The volume of the preparatory trench $\left(V_{t}\right)$ depends on the width of mine field across the strike of developed strata, the digging radius of dragline, the height of its installation in the dump zone and is determined by the Eq. (14):

$$
V_{t}=0.5\left(B_{t}^{t}+B_{t}^{b}\right) \times H_{t} \times L_{p}^{t}
$$


where:

$L_{p}{ }^{t}-$ the average length of the preparatory trench, $\mathrm{m}$.

The amount of coal extracted during the construction of the preparatory trench $\left(V_{c}^{t}\right)$ :

$$
V_{c}^{t}=\sum_{i=1}^{n} \frac{m_{i}}{\sin \alpha_{i}} \times H_{t} \times 0.5\left(B_{t}^{b}+B_{t}^{t}\right) \times\left(1-C_{i}^{o}\right) \times C_{i}^{u}
$$

where:

$m_{i}$ - normal thickness of the $i$-th seam in the strata, $\mathrm{m}$;

$\alpha_{i}-$ dip angle of the $i$-th seam in the strata, degrees;

$C_{l}^{u}$ - coal losses coefficient for underground mining;

$C_{l}^{o}-$ coal losses coefficient for open-pit mining.

A distinctive feature of the technology for constructing the preparatory trench using dragline is its driving to the full depth immediately. Dragline working strokes are made exclusively along the coal seams, which is explained by the design features of the dragline and the conditions of steep coal seams occurrence.

During the preparatory trench driving, stripping of coal seams (pillars) under sediments is conducted. The worked-out layer of the rock-and-coal array is divided by depth into subbenches with a height equal to the digging depth of a hydraulic backhoe (6-7 m).

Initially, the upper subbench is worked out to the width of the stope of the hydraulic backhoe (8-10 m). To do this, the surrounding rocks are loosened along the entire length of the lateral front using drilling and blasting operations with the discharge of rocks to the underlying subbenches.

After that, the remaining coal pillars are excavated with a hydraulic backhoe to a depth equal to the height of subbench with loading in dump trucks. The rock remaining after this is moved by dragline in the scraping mode to the lower edge of the lower subbench, followed by excavation into the lower dump level, forming a route for the dragline's pass.

The sequence of drilling and blasting when mining a rock-and-coal layer using direct dumping is as follows.

Initially, the rock-and-coal stope on the upper subbench is blasted; coal seams are excavated by hydraulic backhoes. After that, dragline in the scraping mode moves the overburden rock to the internal dump.

After that, the stope on the lower subbench is blasted with the same mode of coal extraction and rock excavation, and so on for the lowest subbench.

When blasting a rock-and-coal stope of the upper subbench, one part of the blasted rock remains at the working site. Another part is dumped onto the transport berm of the underlying subbenches.

\section{Modifications of a continuous lateral method for coal pillars surface mining}

The new direct dumping technology of surface coal mining from dead mine pillars presented in the article has three modifications for various conditions.

The first modification is designed for coal seams strata of a high total thickness $(200-800 \mathrm{~m})$ and inclined and steeply dipping and associated with the continuous stepwise mining of the rock-and-coal block and is intended for using dragline for overburden excavation and for coal extraction (Fig. 4). In accordance with this, the height of the layer of coal pillars excavation within the mine field is determined by the dragline's operating parameters - the digging depth and the height of the discharge.

The second modification is designed for inclined and steeply dipping coal seams strata of a high medium total thickness $(100-300 \mathrm{~m})$ and implies using dragline in combination with a hydraulic backhoe for continuous stepwise mining of coal pillars within the mine field. (Fig. 5). The use of hydraulic backhoe can significantly reduce coal losses during surface mining, compared with the use of dragline for this purpose (by 12-18\% (Tyulenev et al., 2017). The thickness of the extracted rock-and-coal layer here is equal to the sediments' thickness and the digging depth of the hydraulic backhoe.

The third modification is intended for selective surface coal mining from pillars of a mine field with coal seams remote from each other (Fig. 6), using dragline and hydraulic backhoe. The thickness of the extracted layer is also determined by the digging depth of the hydraulic backhoe.

The continuous technology of surface mining is used for the extraction of coal pillars by dragline in the boundaries of the fields of closed mines (the first modification) is carried out in four stages (Fig. 3). 

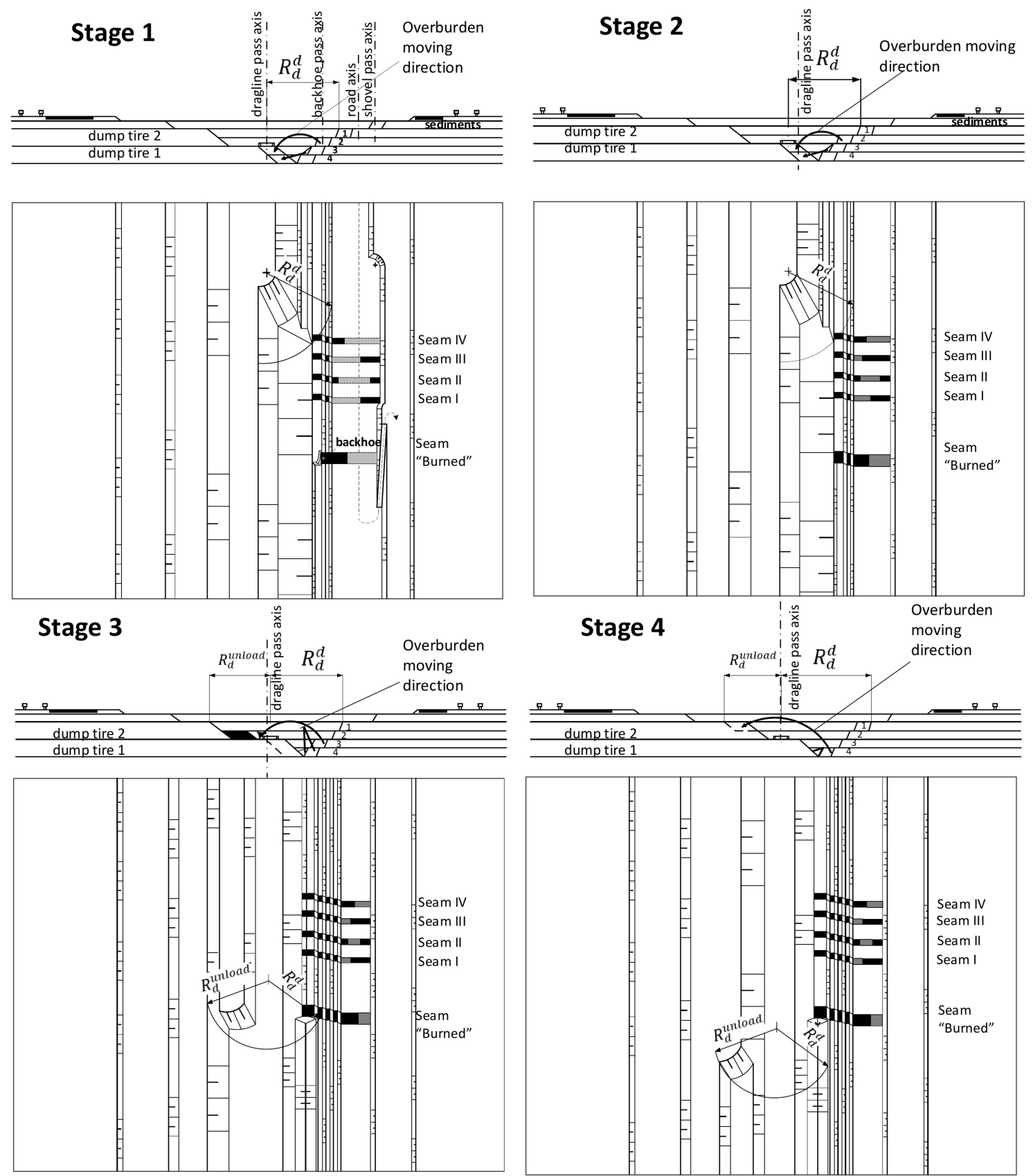

Fig. 3. The scheme of continuous surface mining of coal pillars in a mine field to a depth determined by the dragline's ability to carryoutdirect dumping

At the first stage, the dragline is installed on the upper platform of the lower dump tier and, in the scraping mode, removes the remains of the rock interbeds, partially filling the dump tier 1 .

The second stage is the development of subbench 2. Part of the rock from subbenches 1 and 2 (as a result of blasting displacement) is poured down to the first dump tier. The stopes of subbench 1 and 2 form a temporary bulk, from which the dragline forms the first dump tier.

In the third stage, subbench 3 is developed. The part of the collapse remains in the stope, and the rest is displaced by the blast and is located between the filled capacity of the first dump tier and the slope of the unexploded stope of subbench 4. Dragline places the overburden from the stope of subbench 3 in the lower part of dump tier 2.

At the fourth stage, a feature of the development of the near-bottom rock-and-coal stope of subbench 4 is its location in the clamped area (the cross-hatched area in Fig 4). In the last pass, the dragline develops the stope and fills in the rest of the second dump tier. It should be noted that in order to work out the next stope, the dragline needs to fill the track, while the step of moving across the working front approximately corresponds to the horizontal width of the dump tier. 
The technological scheme of continuous surface mining of a dead mine field using a dragline for excavation of overburden and a hydraulic backhoe for coal extraction (second modification) is presented in Fig. 4. The technology is carried out in four stages to a layer depth equal to the total sediments thickness and a maximum digging depth of a hydraulic backhoe (up to $12 \mathrm{~m}$ ).

At the first stage, a preparatory trench is excavated with a depth equal to sediments thickness across the strike of coal seams within the mine field using a dragline. As a result, the coal seams under sediments are stripped.

At the second stage, the dragline along the strike of the coal seams works out a trench with a depth equal to the thickness of the sediments and with a width along the bottom of $\left(B_{t b}\right)$ equal to:

$$
B_{t}^{b}=2 R_{d}^{d} \times \sin \varphi
$$

where:

$R_{d}^{d}$ - the maximum digging radius of the dragline, m;

$\varphi$ - angle of rotation of the dragline arrow from the axis of its standing, degrees $\left(\psi=35^{0}-40^{0}\right)$.

At the same time, the rock is excavated on the trench side bordering the contours of the mine field.

At the third stage, the remaining coal reserves (pillars) are excavated by hydraulic backhoes at the working depth of digging with the loading of coal into dump trucks located above or at the excavator's standing level. After the coal pillars excavation along the trench's entire length, it is backfilled with loose overburden sediments.

At the fourth stage, an adjacent trench is worked out along the mine field strike with sediments laying on the surface of the internal dump of the previous dragline stope, followed by coal extraction from the safety pillars and backfilling of the worked-out zones with sediments. In a similar sequence, the development of the entire upper level of the mine field is made.

The third modification - the selective technology of coal surface mining from the mine field pillars with coal seams dispersed and separated from each other is shown in Fig. 5.

A distinctive feature of this technology from a continuous excavation (first and second modifications, Fig. 3 and 4 ) is the trenching with a dragline or hydraulic backhoe along one or two adjacent coal seams along their strike and laying sediment rocks along the sides of the trench, followed by excavation pillars of coal. Moreover, after the extraction of coal, the worked-out space is filled up with sediments. Rock interbeds of high thickness are not affected by surface mining; that is, partial mining of pillars is carried out, where there are only separate sections with the inclusion of single or several adjacent coal seams. 

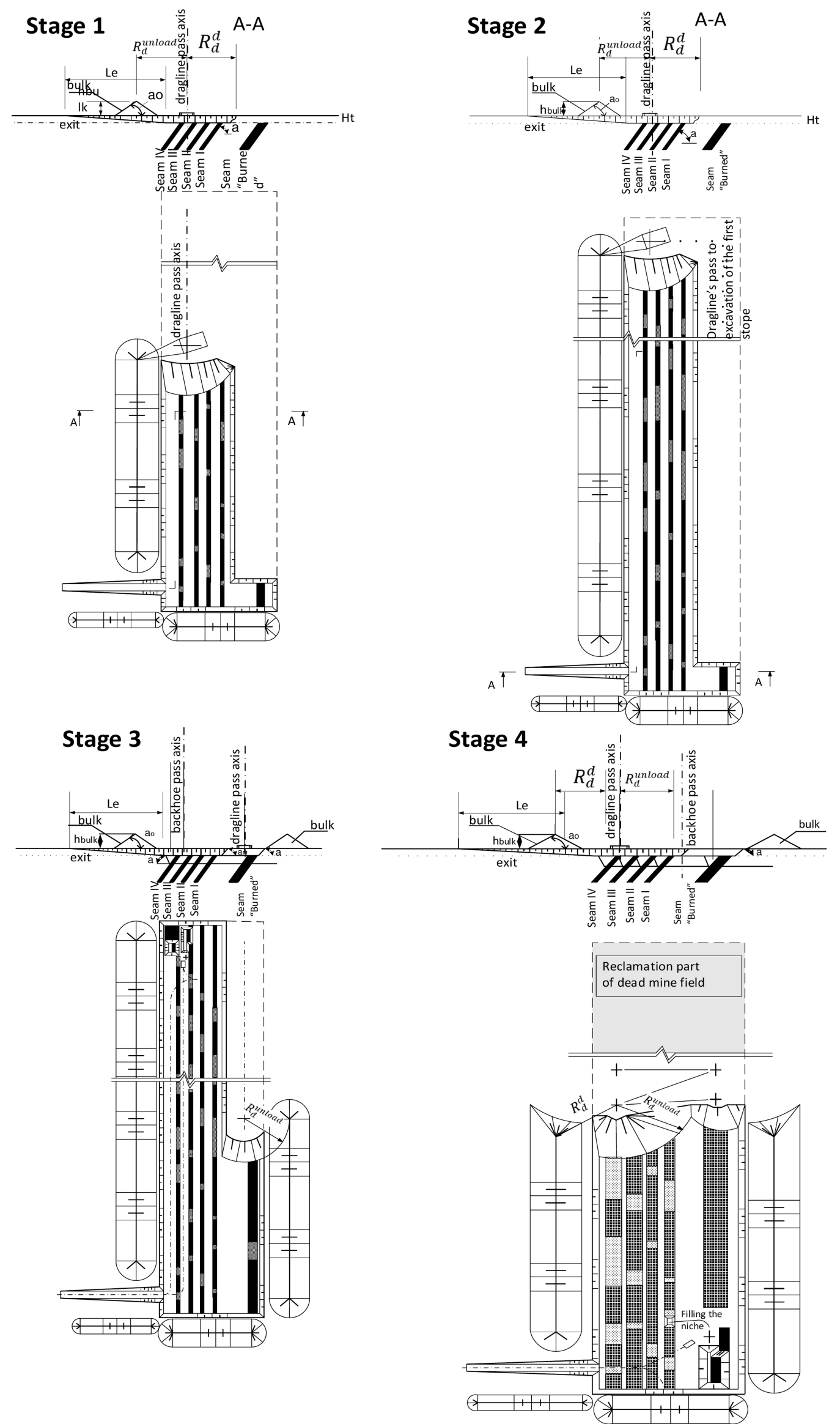

Fig. 4. The scheme of continuous surface mining of the mine field to a depth equal to the sediments thickness and the digging depth of a hydraulic backhoe 
The stages of extraction of coal seams in the third modification of the technology for coal pillars surface mining are associated with the extraction of a specific seam. Therefore, in Fig. 6, the development of surface mining operations from the first to the third stage is associated with the sequential movement of excavators (dragline and hydraulic backhoe) from one trench to another, as coal is extracted and overburden is filled in the worked-out space. The large blocks of overburden in the interbeds thus remain intact.
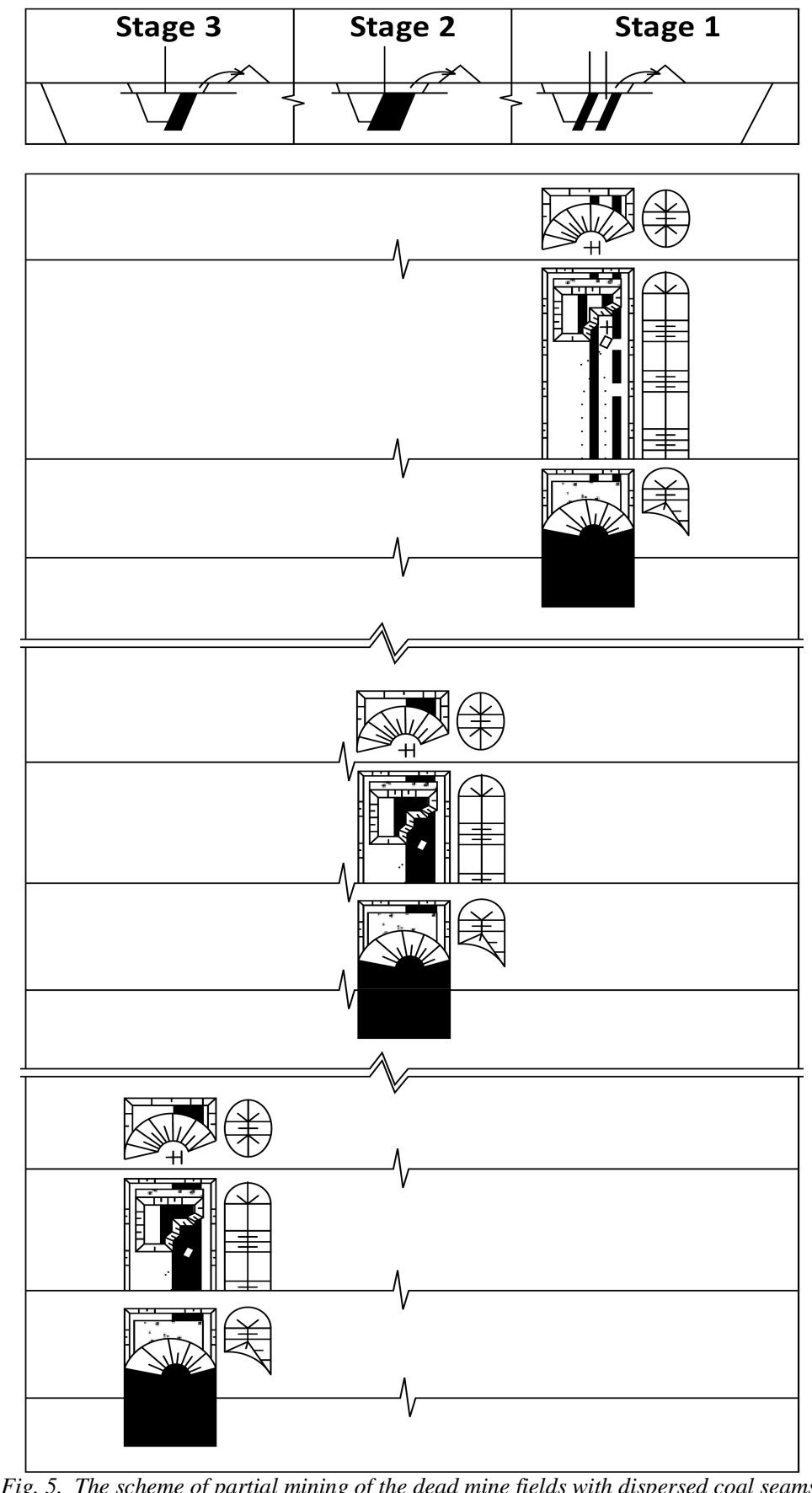

\section{Results}

As it was mentioned above, the use of the layered lateral continuous surface mining method for extraction of the coal reserves remaining in pillars suggests internal dumping, while the deepening longitudinal method widely used today in Kuzbass involves external dumping and expansion of the quarry field as it deepens. Therefore, the use of the lateral continuous mining method for mining inclined and steep coal seams in pillars, proposed by the authors, can significantly reduce the land area occupied by the quarry field and overburden 
dumps, change the more expensive overburden removal to external dumps by dump trucks with its cheap discharging by draglines to the internal dump.

In the present paper, the proposed mining method's main parameters (linear dimensions of the working zone, rock-and-coal layer and quarry field, areas occupied by surface mine and dumps, volumes of the rock mass and overburden) are evaluated for three modifications of lateral continuous mining method. These modifications cover all possible variants of coal pillars surface mining - by draglines (for coal seams stratas of high thickness), by draglines and backhoes (for stratas of medium thickness), as well as for dispersed seams.

The results obtained made it possible to compare the impact of the application of deepening longitudinal and continuous lateral methods of coal pillars miming on the environment - by the area of land occupied by the external dump, its height, and dust emission. A comparison of these coal pillars mining methods was also made accordingly to the costs of transporting overburden.

The essential elements of the layered continuous lateral method of coal pillars surface mining are the width of the working zone $(W Z W)$ and the rock-and coal layer thickness $\left(H_{l}\right)$, safety berm for dragline on the dump side $\left(b_{o}\right)$, width of the dragline stope $\left(A_{d r}\right)$, the dump tier height $\left(H_{t i e r}\right)$. For three modifications of the continuous lateral method of coal pillars mining, the linear parameters were calculated using Equations (1-5), the preparatory trench parameters - Equations (6-13), the volumes of coal and overburden - Equations (14-15) and are presented below.

\section{Quarry field parameters for the first modification of continuous surface mining method}

For the first modification (extraction of overburden and coal with a dragline, for coal seams stratas of a high thickness (200-800 m)), the results of calculations of the linear parameters of the quarry, depending on the total thickness of the strata, are shown in the Tab. 1 (Demirel, 2011). For the pillars, consisting of seams of different total power, the following dragline models are recommended:

a) for total strata thickness up to $200 \mathrm{~m}$ - ESH-11.75 (made in Russia, bucket volume - $11 \mathrm{~m} 3$, boom length $-75 \mathrm{~m}$, annual productivity - $2741324 \mathrm{~m} 3$, specific power consumption $-1.8 \mathrm{kWh} / \mathrm{m} 3$;

b) for total strata thickness 300-400 m - ESH-20.90 (bucket volume - $20 \mathrm{~m} 3$, boom length - $90 \mathrm{~m}$, annual productivity - $4087065 \mathrm{~m} 3$, specific power consumption $-2.2 \mathrm{kWh} / \mathrm{m} 3$ );

c) for total strata thickness $600-800 \mathrm{~m}$ - ESH-25.90 (bucket volume - $25 \mathrm{~m} 3$, boom length - $90 \mathrm{~m}$, annual productivity $-5108832 \mathrm{~m} 3$, specific power consumption $-2.4 \mathrm{kWh} / \mathrm{m} 3)$.

Tab. 1. Dragline model and the parameters of mining method (layer thickness $\left(H_{l}\right)$, width of the working zone (WZW), safety berm for dragline $\left(b_{o}\right)$, width of the dragline stope $\left(A_{d r}\right)$, internal dump tier height $\left.\left(H_{\text {tier }}\right)\right)$, in accordance with the coal seams strata total

\begin{tabular}{ccccccc}
\multicolumn{8}{c}{ thickness $\left(M_{s t}\right)$ in the pillars zone } \\
\hline$M_{s t}[\mathrm{~m}]$ & Dragline & $H_{l}[\mathrm{~m}]$ & WZW $[\mathrm{m}]$ & $b_{o}[\mathrm{~m}]$ & $A_{d r}[\mathrm{~m}]$ & $H_{\text {tier }}[\mathrm{m}]$ \\
200 & ESH-11.75 & 22 & 72.8 & 6.2 & 41 & 15 \\
300 & ESH-20.90 & 31 & 79.7 & 8.4 & 60 & 20 \\
400 & ESH-20.90 & 40 & 80.6 & 8.4 & 60 & 20 \\
600 & ESH-25.90 & 47 & 82.1 & 9.6 & 62 & 30 \\
800 & ESH-25.90 & 53 & 84.2 & 9.6 & 62 & 30 \\
\hline
\end{tabular}

For the first modification (overburden and coal excavating with dragline), the depth of the preparatory trench equals to dragline's digging depth $\left(H_{t}\right)$, and the length of a trench - the total thickness of a coal seams strata $\left(M_{s t}, 200-800 \mathrm{~m}\right)$. The results of preparatory trench parameters' calculations are presented in Tab. 2.

Tab. 2. Preparatory trench parameters (trench depth $\left(H_{t}\right)$, length $\left(L_{t}\right)$, bottom width $\left(B_{t}^{b}\right)$, top width $\left(B_{t}^{t}\right)$, dragline safety berm $\left(Z_{o}\right)$, trench $\left(V_{t}\right)$ and coal $\left(V_{c}^{t}\right)$ volumes $)$, in accordance with dragline model

\begin{tabular}{cccccccc}
\hline Dragline & $\mathrm{H}_{\mathrm{t}}[\mathrm{m}]$ & $\mathrm{L}_{\mathrm{t}}[\mathrm{m}]$ & $\mathrm{B}_{\mathrm{t}}^{\mathrm{b}}[\mathrm{m}]$ & $\mathrm{B}_{\mathrm{t}}^{\mathrm{t}}[\mathrm{m}]$ & $\mathrm{Z}_{\mathrm{o}}[\mathrm{m}]$ & $\mathrm{V}_{\mathrm{t}}\left[\mathrm{m}^{3}\right]$ & $\mathrm{V}_{\mathrm{c}}^{\mathrm{t}}\left[\mathrm{m}^{3}\right]$ \\
\hline ESH-11.75 & 38 & 200 & 57.76 & 13.8 & 4.2 & 271928 & 40687 \\
ESH-20.90 & 43 & 300 & 77.4 & 17.2 & 5.8 & 610170 & 95644 \\
ESH-20.90 & 43 & 400 & 77.4 & 17.2 & 5.8 & 813560 & 139119 \\
ESH-25.90 & 47 & 600 & 87.89 & 19.4 & 6.2 & 1512789 & 269466 \\
ESH-25.90 & 47 & 800 & 90.24 & 19.4 & 6.2 & 2061232 & 330441 \\
\hline
\end{tabular}


According to the layer's height, the volumetric parameters of the rock-and-coal layer and the volumes of coal and overburden in the quarry are calculated using generally accepted equations (Tanaino and Cheskidov, 1999) and shown in Tab. 3 and 4.

Tab. 3. The working rock-and-coal layer parameters (layer thickness $\left(H_{l}\right)$, rock mass volume in the layer $\left(V_{r m}\right)$, coal volume in the

\begin{tabular}{cccc}
\multicolumn{4}{c}{ layer $\left(V_{c l}\right)$, the weight of the coal in the layer $\left.\left(W_{c l}\right)\right)$} \\
\hline$H_{l}[\mathrm{~m}]$ & $V_{r m}\left[\mathrm{~m}^{3}\right]$ & $V_{c l}\left[\mathrm{~m}^{3}\right]$ & $W_{c l}[\mathrm{t}]$ \\
22 & 320320 & 47928 & 68058 \\
31 & 741210 & 116185 & 164982 \\
40 & 1289600 & 220522 & 313141 \\
47 & 2315220 & 412399 & 585606 \\
53 & 3570080 & 572328 & 812706 \\
\hline
\end{tabular}

Tab. 4. The quarry field parameter (quarry depth $\left(H_{q}\right)$, number of layers $\left(n_{l}\right)$, overburden volume $\left(V_{q o}\right)$, coal volume $\left(V_{q c}\right)$ in the

\begin{tabular}{ccccc}
\multicolumn{5}{c}{ quarry) in accordance with the layer thickness $\left(H_{l}\right)$} \\
\hline$H_{l}[\mathrm{~m}]$ & $n_{l}$ & $H_{q}[\mathrm{~m}]$ & $V_{q o}\left[\mathrm{~m}^{3}\right]$ & $V_{q c}\left[\mathrm{~m}^{3}\right]$ \\
22 & 4 & 88 & 1089568 & 191712 \\
31 & 3 & 93 & 1875076 & 348554 \\
40 & 3 & 120 & 3207235 & 661565 \\
47 & 3 & 141 & 5708464 & 1237196 \\
53 & 3 & 159 & 8993255 & 1716985 \\
\hline
\end{tabular}

\section{Quarry field parameters for the second modification of the continuous surface mining method}

For the second modification (extraction of overburden with a dragline, and coal - with a hydraulic backhoe (for the stratas of medium thickness $(100-300 \mathrm{~m})$ ), the specific distinction is the layer thickness $H_{l}$, which is equal to the digging depth of a backhoe $(5-15 \mathrm{~m})$. The subbench is determined by efficient scooping of the coal seam with minimal losses (Tyulenevet al, 2017).

For different coal seams strata thickness $\left(M_{s t}\right)$, different models of backhoes were recommended. Thus, for $M_{s t}$ of $100 \mathrm{~m}$, Hitachi EX-1200, Caterpillar 6015, etc. with bucket volume of 5-8 $\mathrm{m}^{3}$ was proposed, for $M_{s t}$ of 150-200 m - Komatsu PC-2000, Hitachi EX-1900, Liebherr R 9150, etc. (10-12 $\mathrm{m}^{3}$ ), for $M_{s t}$ of 250-300 m Komatsu PC-3000, Hitachi EX-2600, Liebherr R 9350 (15-18 m³).

The results of calculations of the linear parameters of the quarry, depending on the total thickness of the strata, are shown in Tab. 5.

Tab. 5. Backhoe bucket volume, the parameters of mining method (layer thickness ( $\mathrm{Hl}$ ), width of the working zone (WZW), safety berm for backhoe on the subbench (b), width of the backhoe stope (Abh), backhoe subbench height ( $\left.H_{s b}\right)$, internal dump tier height

\begin{tabular}{|c|c|c|c|c|c|c|c|}
\hline$M_{s t}[\mathrm{~m}]$ & $\begin{array}{c}\text { Bucket volume } \\
{\left[\mathrm{m}^{3}\right]}\end{array}$ & $H_{l}[\mathrm{~m}]$ & $\mathrm{WZW}[\mathrm{m}]$ & $b[\mathrm{~m}]$ & $A_{b h}[\mathrm{~m}]$ & $H_{s b}[\mathrm{~m}]$ & $H_{\text {tier }}[\mathrm{m}]$ \\
\hline 100 & $5-8$ & 5 & 70.4 & 1.9 & 23.4 & 4 & 20 \\
\hline 150 & $10-12$ & 10 & 76.8 & 2.4 & 25.5 & 6 & 20 \\
\hline 200 & $10-12$ & 10 & 78.8 & 2.4 & 25.5 & 6 & 20 \\
\hline 250 & $15-18$ & 15 & 80.4 & 3.6 & 28.2 & 8 & 30 \\
\hline 300 & $15-18$ & 15 & 82.2 & 3.6 & 28.2 & 8 & 30 \\
\hline
\end{tabular}

Preparatory trench depth for the second modification is equal to the thickness of the sediments or the rockand-coal layer thickness. The length of a trench is also equal to the total thickness of the coal seams strata $\left(M_{s t}\right.$, 100-300 m). The results of the calculation of linear and volumetric parameters of the trench are shown in Tab. 6 .

Tab. 6. Preparatory trench parameters (trench depth $\left(H_{t}\right)$, length $\left(L_{t}\right)$, bottom width $\left(B_{t}^{b}\right)$, top width $\left(B_{t}^{t}\right)$, dragline safety berm $\left(Z_{o}\right)$, trench $\left(V_{t}\right)$ and coal $\left(V_{c}^{t}\right)$ volumes $)$, in accordance with dragline model

\begin{tabular}{cccccccc}
\hline Dragline & $H_{t}[\mathrm{~m}]$ & $L_{t}[\mathrm{~m}]$ & $B_{t}^{b}[\mathrm{~m}]$ & $B_{t}^{t}[\mathrm{~m}]$ & $Z_{o}[\mathrm{~m}]$ & $V_{t}\left[\mathrm{~m}^{3}\right]$ & $V_{c}^{t}\left[\mathrm{~m}^{3}\right]$ \\
\hline ESH-11.75 & 5 & 100 & 13.8 & 19.3 & 4.2 & 8275 & 2476 \\
ESH-20.90 & 10 & 150 & 17.2 & 28.2 & 5.8 & 34050 & 10675 \\
ESH-20.90 & 10 & 200 & 17.2 & 28.2 & 5.8 & 45400 & 15527 \\
\hline
\end{tabular}




\begin{tabular}{llllllll}
\hline ESH-25.90 & 15 & 250 & 19.4 & 35.9 & 6.2 & 103688 & 44326 \\
ESH-25.90 & 15 & 300 & 19.4 & 35.9 & 6.2 & 124425 & 53192 \\
\hline
\end{tabular}

For the second modification of the continuous lateral method of coal pillars mining, the volumetric parameters of the rock-and-coal layer, as well as the total volumes of coal and overburden in the quarry, according to the layer's height, are shown in Tables 7 and 8.

Tab. 7. The working rock-and-coal layer parameters (layer thickness ( $\mathrm{Hl}$ ), rock mass volume in the layer (Vrm), coal volume in the

\begin{tabular}{cccc}
\multicolumn{4}{c}{ layer $\left(V_{c l}\right)$, the weight of the coal in the layer $\left.\left(W_{c l}\right)\right)$} \\
\hline$H_{l}[\mathrm{~m}]$ & $V_{r m}\left[\mathrm{~m}^{3}\right]$ & $V_{c l}\left[\mathrm{~m}^{3}\right]$ & $W_{c l}[\mathrm{t}]$ \\
5 & 35200 & 10534 & 14958 \\
10 & 115200 & 36115 & 51284 \\
10 & 157600 & 53899 & 76537 \\
15 & 301500 & 128891 & 183026 \\
15 & 369900 & 72529 & 102992 \\
\hline
\end{tabular}

Tab. 8. The quarry field parameter (quarry depth (Hq), number of layers ( $\mathrm{nl}$ ), overburden volume (Vqo), coal volume (Vqc) in the

\begin{tabular}{ccccc}
\multicolumn{5}{c}{ quarry), in accordance with the layer thickness $(\mathrm{Hl})$} \\
\hline$H_{l}[\mathrm{~m}]$ & $n_{l}$ & $H_{q}[\mathrm{~m}]$ & $V_{q o}\left[\mathrm{~m}^{3}\right]$ & $V_{q c}\left[\mathrm{~m}^{3}\right]$ \\
\hline 5 & 16 & 80 & 394662 & 168538 \\
10 & 9 & 90 & 711763 & 325037 \\
10 & 12 & 120 & 1244410 & 646790 \\
15 & 12 & 141 & 2071305 & 1546695 \\
15 & 11 & 165 & 3271076 & 1797824 \\
\hline
\end{tabular}

\section{Quarry field parameters for the third modification of continuous surface mining method}

The third modification of the continuous surface mining method, as well as the second one, implies overburden extracting with the dragline and coal - with the hydraulic backhoe. The total thickness of coal seams strata, like for the second modification, is $100-300 \mathrm{~m}$. Since the outstanding feature of the third modification is mining the strata in pillars along the strike (due to distanced separate coal seams), the length of the quarry field is longer (600-1200 m), and the width of the working zone - narrower. Therefore, the height of the internal dump tier equals the thickness of the rock-and-coal layer. The results of calculations of the linear parameters of the quarry for the third modification are shown in Tab. 9.

Tab. 9. Backhoe bucket volume, the parameters of mining method (layer thickness $\left(H_{l}\right)$, width of the working zone (WZW), safety berm for backhoe on the subbench $(b)$, width of the backhoe stope $\left(A_{b h}\right)$, backhoe subbench height $\left(H_{s b}\right)$, internal dump tier height $\left.\left(H_{\text {tier }}\right)\right)$, in

\begin{tabular}{|c|c|c|c|c|c|c|c|}
\hline$M_{s t}[\mathbf{m}]$ & $\begin{array}{c}\text { Bucket volume } \\
{\left[\mathbf{m}^{3}\right]}\end{array}$ & $H_{l}[\mathbf{m}]$ & $\mathrm{WZW}[\mathrm{m}]$ & $b[\mathrm{~m}]$ & $A_{b h}[\mathbf{m}]$ & $\boldsymbol{H}_{s b}[\mathbf{m}]$ & $\boldsymbol{H}_{\text {tier }}[\mathrm{m}]$ \\
\hline 100 & $5-8$ & 5 & 41,4 & 1.9 & 23.4 & 4 & 5 \\
\hline 150 & $10-12$ & 10 & 43,5 & 2.4 & 25.5 & 6 & 10 \\
\hline 200 & $10-12$ & 10 & 43,5 & 2.4 & 25.5 & 6 & 10 \\
\hline 250 & $15-18$ & 15 & 46,2 & 3.6 & 28.2 & 8 & 15 \\
\hline 300 & $15-18$ & 15 & 46,2 & 3.6 & 28.2 & 8 & 15 \\
\hline
\end{tabular}

The linear parameters of the preparatory trench for the third modification of coal pillars' lateral continuous mining method are equal to the second modification due to the same conditions - working the trench to the depth, equal to the sediments thickness or layer height.

The volumetric parameters of the rock-and-coal layer, as well as the volumes of coal and overburden in the quarry, for the second modification of the continuous lateral mining method, are shown in Tab. 10 and 11. 
Tab. 10. The working rock-and-coal layer parameters (layer thickness $\left(H_{l}\right)$, rock mass volume in the layer $\left(V_{r m}\right)$, coal volume in the

\begin{tabular}{cccc}
\multicolumn{4}{c}{ layer $\left(V_{c l}\right)$, the weight of the coal in the layer $\left.\left(W_{c l}\right)\right)$} \\
\hline$H_{l}[\mathrm{~m}]$ & $V_{r m}\left[\mathrm{~m}^{3}\right]$ & $V_{c l}\left[\mathrm{~m}^{3}\right]$ & $W_{c l}[\mathrm{t}]$ \\
5 & 124200 & 37167 & 52777 \\
10 & 348000 & 109098 & 154919 \\
10 & 435000 & 148770 & 211253 \\
15 & 831600 & 355509 & 504823 \\
15 & 369900 & 72529 & 102992 \\
\hline
\end{tabular}

Tab. 11. The quarry field parameter (quarry depth $\left(H_{q}\right)$, number of layers $\left(n_{l}\right)$, overburden volume $\left(V_{q o}\right)$, coal volume $\left(V_{q c}\right)$ in the

\begin{tabular}{ccccc}
\multicolumn{5}{c}{ quarry), in accordance with the layer thickness $\left(H_{l}\right)$} \\
\hline$H_{l}[\mathrm{~m}]$ & $n_{l}$ & $H_{q}[\mathrm{~m}]$ & $V_{q o}\left[\mathrm{~m}^{3}\right]$ & $V_{q c}\left[\mathrm{~m}^{3}\right]$ \\
\hline 5 & 16 & 80 & 1392530 & 594670 \\
10 & 9 & 90 & 2150118 & 981882 \\
10 & 12 & 120 & 3434760 & 1785240 \\
15 & 12 & 141 & 5713092 & 4266108 \\
15 & 11 & 165 & 7353953 & 1793647 \\
\hline
\end{tabular}

\section{Results of comparison of the dumping parameters and its influence on the environment for proposed continuous lateral and currently used deepening longitudinal methods of coal pillars mining}

For comparing the dumping parameters for different coal pillars' mining methods, the following provisions were applied:

1) The main source of disturbances in relief and dust emissions are external dumps, into which, with the deepening longitudinal method, the entire overburden is dumped, and with the continuous lateral method - only the sediments.

2) For the deepening longitudinal mining method, all the overburden is moved to the external dump by the dump trucks, and for the continuous lateral method - to the internal dump by dragline (except sediments).

3) To calculate the annual values of emissions of the rock dust from external dumps in Kuzbass, the following indicators were taken: specific dust emissions taking into account the wind speed on the surface of the dump and the natural water cut of the field is $10-6 \mathrm{~g} / \mathrm{m}^{2} \cdot \mathrm{sec}$; the number of dry, windy days without snow in the year is 82 .

The results of comparing the parameters of external dumping and its environmental impact for deepening longitudinal and continuous lateral mining methods are shown in Fig.6. 


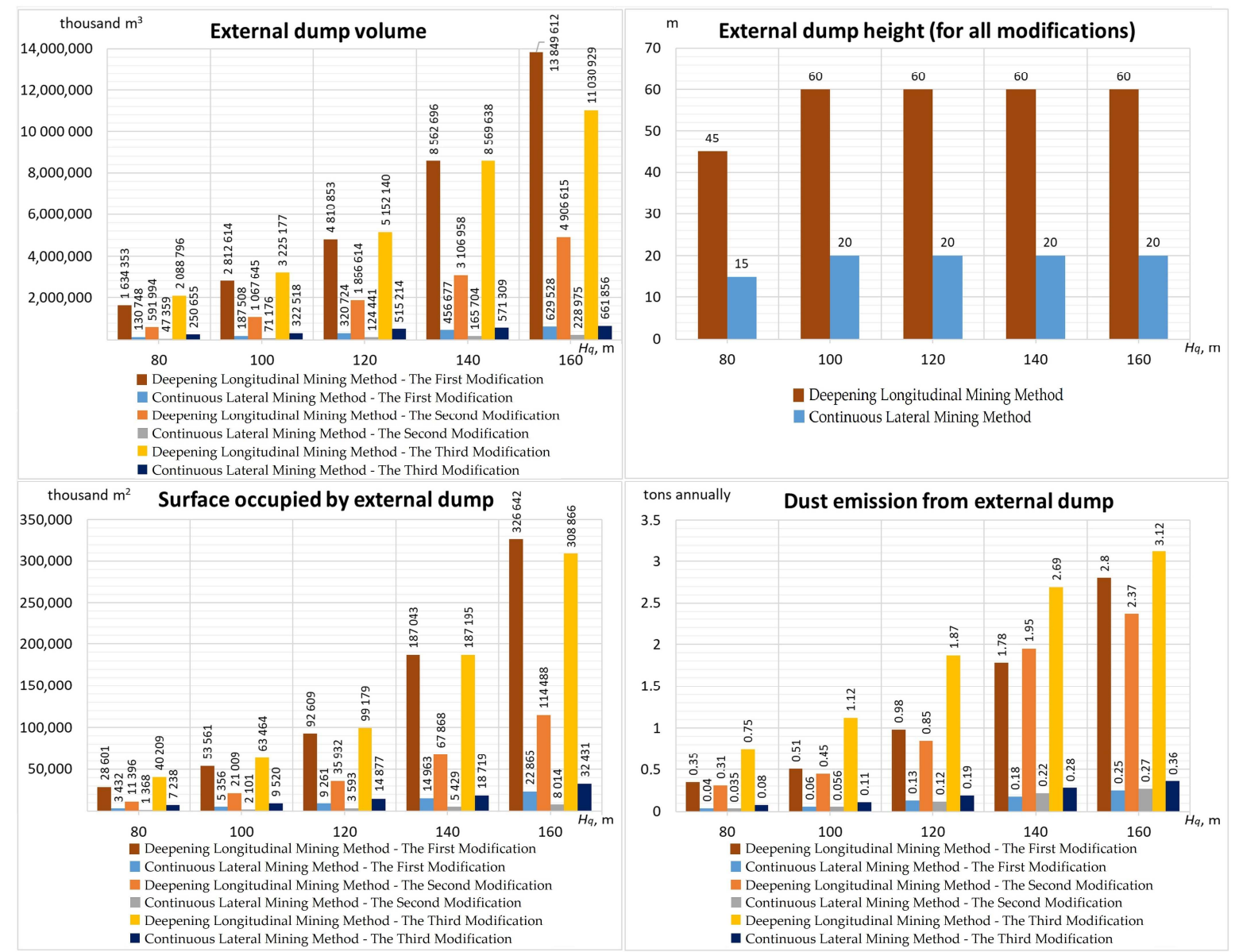

Fig. 6. Comparison of the external dumping parameters and their influence on the environment for deepening longitudinal and continuous lateral mining methods.

\section{Results of business indicators comparison for different methods of coal pillars mining}

To compare deepening longitudinal and continuous lateral coal pillars surface mining methods, such business indicators as values of consumption and costs of diesel fuel (for dump trucks) and electric power (for draglines), the total expenses of overburden transporting were used. The uniform calculations are made for all three modifications due to the small gaps in rock-end coal volumes in the quarry field between them. The amount of equipment for moving overburden to the external dump (dump trucks) and the internal dump (draglines) is determined based on the volume of overburden within the quarry and the productivity of the equipment. For the calculation, the following dump trucks models were used:

A) for deepening longitudinal mining method with a relatively bigger volume of overburden, moved to the external dump - Komatsu HD1500-8 (carrying capacity - 172 tons or $92 \mathrm{~m}^{3}$, annual productivity $-2643280 \mathrm{~m}^{3}$, fuel consumption rate - 1070 liters per 12 hours shift);

B) for continuous lateral mining method with a relatively smaller volume of overburden, moved to the external dump - Komatsu HD785-7 (carrying capacity - 91 tons or $48 \mathrm{~m}^{3}$, annual productivity $-1379100 \mathrm{~m}^{3}$, fuel consumption rate -620 liters per 12 hours shift).

The annual productivity of draglines is listed above. Comparison of equipment number for deepening longitudinal and continuous lateral methods of coal pillars surface mining is shown in Tab. 12.

Tab. 12. The number of draglines (DRG) and dump trucks (DT) used for overburden transporting, in accordance with coal pillars mining

\begin{tabular}{|c|c|c|c|c|c|c|c|c|c|}
\hline \multicolumn{2}{|c|}{$H_{q}=80[\mathrm{~m}]$} & \multicolumn{2}{|c|}{$H_{q}=100[\mathrm{~m}]$} & \multicolumn{2}{|c|}{$H_{q}=120[\mathrm{~m}]$} & \multicolumn{2}{|c|}{$H_{q}=140[\mathrm{~m}]$} & \multicolumn{2}{|c|}{$H_{q}=160[\mathrm{~m}]$} \\
\hline$D R G$ & $D T$ & $D R G$ & $D T$ & $D R G$ & $D T$ & $D R G$ & $D T$ & $D R G$ & $D T$ \\
\hline \multicolumn{10}{|c|}{ Deepening longitudinal mining method } \\
\hline 0 & 2 & 0 & 2 & 0 & 3 & 0 & 4 & 0 & 5 \\
\hline \multicolumn{10}{|c|}{ Continuous lateral mining method } \\
\hline 1 & 1 & 1 & 1 & 1 & 1 & 1 & 1 & 2 & 1 \\
\hline
\end{tabular}


To define diesel fuel consumption, the average distance to the external dump was taken as $1.5 \mathrm{~km}$. Comparison of diesel fuel and electricity power consumption for overburden transportation for deepening longitudinal and continuous lateral methods of coal pillars surface mining is shown in Tab. 13.

Tab. 13. Diesel fuel $(D F)$ and electricity power (EP) consumption for overburden transporting by dump trucks and draglines respectively, in accordance with selected mining method and pit depth $(\mathrm{Hq})$

\begin{tabular}{|c|c|c|c|c|c|c|c|c|c|}
\hline \multicolumn{2}{|c|}{$H_{q}=80[\mathrm{~m})$} & \multicolumn{2}{|c|}{$H_{q}=100[\mathrm{~m}]$} & \multicolumn{2}{|c|}{$H_{q}=120[\mathrm{~m}]$} & \multicolumn{2}{|c|}{$H_{q}=140[\mathrm{~m}]$} & \multicolumn{2}{|c|}{$H_{q}=160[\mathrm{~m}]$} \\
\hline $\begin{array}{l}D F \\
{[\mathrm{t})}\end{array}$ & $E P[\mathrm{~kW}]$ & $\begin{array}{c}D F \\
{[\mathrm{t}]}\end{array}$ & $\begin{array}{c}E P \\
{[\mathrm{~kW}]}\end{array}$ & $\begin{array}{c}D F \\
{[\mathrm{t}]}\end{array}$ & $\begin{array}{c}E P[\mathrm{~kW} \\
]\end{array}$ & $\begin{array}{l}D F \\
{[\mathrm{t}]} \\
\end{array}$ & $\begin{array}{c}E P \\
{[\mathrm{~kW}]}\end{array}$ & $\begin{array}{c}D F \\
{[\mathrm{t}]}\end{array}$ & $\begin{array}{c}E P \\
{[\mathrm{~kW}]}\end{array}$ \\
\hline \multicolumn{10}{|c|}{ Deepening longitudinal mining method } \\
\hline 1562 & 0 & 1562 & 0 & 2343 & 0 & 3124 & 0 & 3905 & 0 \\
\hline \multicolumn{10}{|c|}{ Continuous lateral mining method } \\
\hline 382 & 1726 & 382 & 3713 & 382 & 6350 & 382 & 12079 & 382 & 38473 \\
\hline
\end{tabular}

Comparison of the costs of diesel fuel and electricity power consumption for overburden transportation for deepening longitudinal and continuous lateral methods of coal pillars mining is shown in Tab.14. The price of 1 ton of diesel fuel in Kuzbass was taken as $307 \mathrm{USD}, 1 \mathrm{~kW}$ of electricity power - $0.013 \mathrm{USD}$.

Tab. 14. Costs on overburden transporting (thousand USD): diesel fuel (DF) and electricity power (EP) consumption, in accordance

\begin{tabular}{|c|c|c|c|c|c|c|c|c|c|}
\hline \multirow{2}{*}{$\begin{array}{c}H_{q}=80[\mathrm{~m}] \\
D F\end{array}$} & \multicolumn{3}{|c|}{$H_{q}=100[\mathrm{~m}]$} & \multicolumn{2}{|c|}{$H_{q}=120[\mathrm{~m}]$} & \multicolumn{2}{|c|}{$H_{q}=140[\mathrm{~m}]$} & \multicolumn{2}{|c|}{$H_{q}=160[\mathrm{~m}]$} \\
\hline & $E P$ & $D F$ & $E P$ & $D F$ & $E P$ & $D F$ & $E P$ & $D F$ & $E P$ \\
\hline \multicolumn{10}{|c|}{ Deepening longitudinal mining method } \\
\hline 475.39 & 0 & 475.39 & 0 & 713.09 & 0 & 950.78 & 0 & 1188.48 & 0 \\
\hline \multicolumn{10}{|c|}{ Continuous lateral mining method } \\
\hline 116.26 & 24.76 & 116.26 & 33.27 & 116.26 & 51.11 & 116.26 & 73.31 & 116.26 & 92.01 \\
\hline
\end{tabular}

Comparison of the total costs of overburden transporting for deepening longitudinal and continuous lateral methods of coal pillars surface mining, depending on the quarry depth, is shown in Fig. 7.

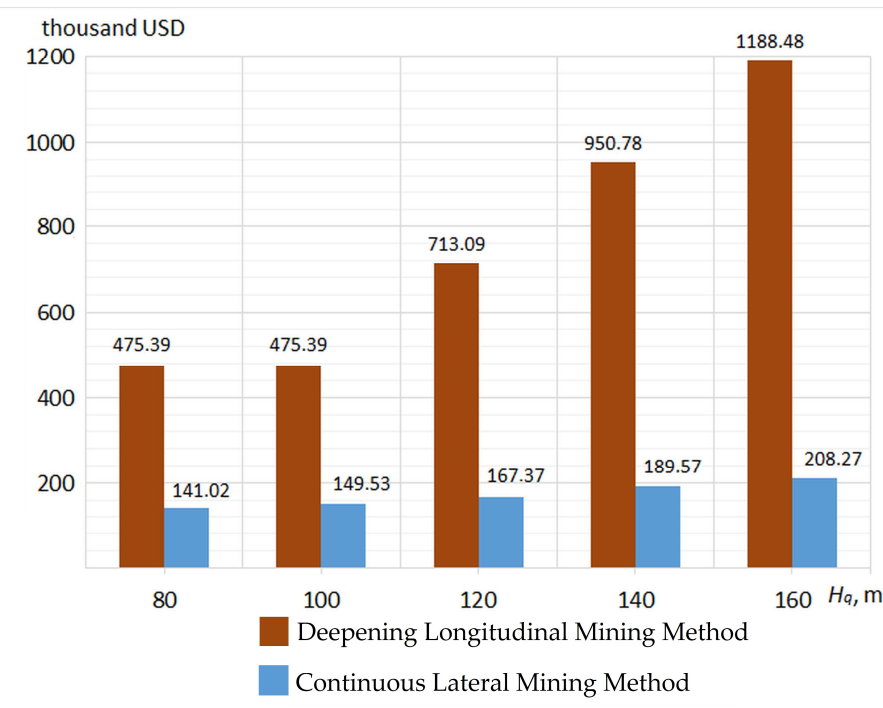

Fig. 7. Comparison of the total costs of overburden transporting for deepening longitudinal and continuous lateral mining methods 


\section{Discussion}

When analyzing the parameters of the continuous lateral method of mining the coal pillars of closed mines, it is obvious that it has weighty advantages over the deepening longitudinal method to reduce environmental damage (mainly large land plots and dust emission), and overburden transporting costs.

First, the continuous lateral mining method is applicable for mining coal pillars of various types of seams low, inclined, and steeply dipping, with large and medium thickness, closely spaced or dispersed. Proposed modifications of the continuous lateral method of coal pillars surface mining are distinguished by the equipment used, the parameters of the extracted layer and the working zone, as well as the preparatory trench.

Thus, the first modification, designed for developing pillars of coal seams strata of a high total thickness (200-800 m), involves the use of dragline to extract both overburden and coal. This modification is distinguished by the maximum thickness of the worked-out rock-coal layer $(22-53 \mathrm{~m})$ and the width of the working zone $(72.8$ $84.2 \mathrm{~m}$, Tab. 1). The height of the internal dump tier does not exceed the thickness of the extracted layer. Depending on the total coal seams strata thickness and the depth of the quarry, it is planned to use draglines with a bucket capacity of $11-25 \mathrm{~m}^{3}$. Therefore, a preparatory trench is also carried out to the digging depth of a dragline (38-47 m, Tab. 2). The large linear dimensions of the extracted layer and the preparatory trench determine the large volumes of coal and overburden in them (Tab. 3), as well as a small number of layers (3-4) over the entire depth of the quarry (88-159 m, Tab. 4).

Unlike the first, the second modification of the continuous lateral method of coal pillars surface mining is designed for extracting pillars in the strata of the seams with medium thickness $(100-300 \mathrm{~m})$. Therefore, it is proposed to use hydraulic backhoes with a bucket capacity of $5-18 \mathrm{~m}^{3}$ for the complete extraction of coal. Therefore, the main difference of the second modification is the low thickness of the extracted layer, equal to backhoe digging depth $(5-15 \mathrm{~m})$, which leads to a smaller width of the working zone (70.4-82.2 m) and a slower deepening of mining operations with more complete coal extraction (Tab. 5). Each tier of the internal dump (20$30 \mathrm{~m}$ height) is filled with the overburden from 2-4 layers. The linear and volumetric parameters of the preparatory trench for the second modification (Tab. 6) are also much smaller than for the first one due to the relatively small depth, equal to the layer thickness. The volumes of coal and overburden in each extracted layer for the second modification (Tab. 7) are also less than for the first one. However, the volumes of overburden and coal in the entire quarry for the first and second modifications are approximately the same at a similar quarry depth (Tab. 4 and 8).

The third modification of the continuous lateral method of coal pillars surface mining means, in fact, working a few preparatory trenches (one for each seam) with dragline to the hydraulic backhoe digging depth (5$18 \mathrm{~m}$ ), which also determines the thickness of the extracted layer (Tab. 9). The width of the working zone is almost half as much as for the first and second modifications, and the overburden from each layer is moved to the internal dump, the height of each tier of which is equal to the thickness of the layer. Each layer in the third modification contains relatively small volumes of coal and overburden (Tab. 10), while the number of layers as the pit deepens can be quite significant (9-16), and its total volumes can be similar to the first and second modifications (Tab. 11). In many respects, this is a consequence of the greater length of the quarry field (up to $1200 \mathrm{~m}$ ) due to the development of coal seams strata along the strike.

It is important to note that despite the differences in the technologies for coal and overburden extraction in each modification, the total overburden volumes within the boundaries of the quarry field differ by no more than $2.5 \%$ (Tab. $4,8,11$ ). That leads to similar volumes of the internal dump, and to an equal reduction of the land area occupied by the external dump and the dust emissions from it.

Secondly, along with smaller overburden volumes in the continuous lateral mining method in all three modifications of the coal pillars mining, up to $95 \%$ of it is located in an internal dump, which maximum height is equal to the final depth of the quarry. In this case, only the sediments (partially or completely) are placed in the external dump. Therefore, despite the inevitable dumping of a small external dump with continuous lateral mining method, its volumes are 12-19 times less than with deepening longitudinal method, depending on the modification and depth of the quarry (Fig. 6). Accordingly, the area of land occupied by an external dump, with a transverse system for developing coal pillars, is 11-13 times less than with a longitudinal one. Along with this, the height of the external dump, determined by the dump slope stability conditions, is also 3 times smaller for the continuous lateral mining method than for the deepening longitudinal method (Fig. 6).

It is especially important that as the quarry depth increases two times (from 80 to $160 \mathrm{~m}$ ), the external dump area with deepening longitudinal method of coal pillars mining increases 14.5 times, while with continuous lateral method - in 7.5 times (Fig. 6). Moreover, as a consequence of each modification's characteristics (different widths of the working zone and the length of the quarry), the smallest volumes of overburden placed in the external dump and its area are characteristic of the second modification and the largest - of the third one.

When choosing the surface mining method for extraction, the coal pillars of closed mines are significantly less dust emission in the continuous lateral mining method due to the smaller surface area of the external dump. The data in Fig. 6 allows us to conclude that dust emission from an external dump with continuous lateral mining 
method is 10-13 times less than with a deepening longitudinal one and for all three modifications. For the development of dispersed coal seams in pillars (third modification), it is especially important that as the pit depth increases from 80 to $160 \mathrm{~m}$, dust emission increases 3.5 times for the continuous lateral mining method and 5 times for the deepening longitudinal method, reaching 3 tons annually.

Thus, the calculation results clearly indicate that it is possible to reduce the environmental damage caused by coal pillars surface mining when using the continuous lateral mining method.

Thirdly, from an economic point of view, the continuous lateral mining method of coal pillars mining is more profitable than the deepening longitudinal one. This is achieved by replacing the dump trucks with draglines for moving overburden to the dump, while the number of dump trucks with deepening longitudinal method (2-5, depending on the depth of the quarry) is higher than with a transverse (1). It is also higher than the number of draglines (1-2), which is explained by the higher productivity of the latter (Tab. 12). At the same time, a dump truck of lower carrying capacity can be used for continuous lateral mining method than for the deepening longitudinal one (91 and 172 tons, respectively), and the distance of transportation of overburden to an external dump will also be minimal. It is important to note that despite the fact that higher price of dragline than dump trucks (3-3.5 times), the costs of their maintenance are much lower than dump trucks. The service life (30 years or more) is significantly higher compared to dump trucks (7-9 years at maximum load), which allows getting draglines on lease for the period of mining the pillars (4-8 years).

Comparing the costs of diesel fuel for dump trucks and electricity for draglines (Tab. 13 - physical measures, Tab. 14 - monetary estimates) indicates the advantage of the latter, regardless of modification of continuous lateral mining method. As a result, the total cost of overburden transporting with continuous lateral mining method is 3.5-5.5 times lower than with a deepening longitudinal one (depending on the quarry depth), as shown in Fig. 7. The most important fact here is that with an increase in the quarry depth twice (from 80 to 160 $\mathrm{m}$ ), the total cost of overburden transporting with continuous lateral mining method increase 1.4 times, while with a deepening longitudinal method - in 2.5 times.

Thus, there are environmental and economic advantages of using the continuous lateral method for mining the coal pillars of closed mines over deepening longitudinal one. The use of block-and-layer technology for all three modifications provides avoiding the main restrictions of continuous lateral mining method - applicability only to low dipping deposits.

Along with this, it is important to highlight a number of limitations for applying the continuous lateral method for mining the coal pillars of closed mines presented in the article, which are associated with the special conditions of the closed mines' fields and coal deposits in general:

1. The sites of closed coal mines, on the surface of which valuable agricultural lands, conservation zones, historical monuments are located, as a result of which the license for surface mining cannot be issued.

2. Deposits of low-quality coal (high ash and low calorific value) and the cheap grades of coal, as well as with the seams of a low average thickness (less than $5 \mathrm{~m}$ ). The surface of closed mines' pillars in such deposits, as a rule, is economically impractical.

3. Deposits of coal with a high density of tectonic disturbances leading to the presence of large zones barren of coal. In this case, a significant number of blocks in several layers will contain only overburden, which is extracted without coal. That will greatly complicate the location of the internal dump in the worked-out space of the quarry.

At the same time, in coal clusters with a high concentration of mining operations, both underground and surface (including Kuzbass), these restrictions are associated with specific areas that make up a small part of the fields of closed mines suitable for mining remained coal pillars in the surface way.

\section{Conclusions}

When coal mining is developing in the old coal basins, many underground coal mines deplete their reserves and get closed. At the same time, in the near-surface zone of the first floor of the mine field, in the pillars of different origin, significant coal reserves remain suitable for surface mining. Under favorable conditions (flat bedding of thick seams), surface coal mining from pillars is carried with the lateral method to a quarry depth limited by the depth of pillars, filling the internal dump. However, such conditions are relatively rare since the underground method of coal mining is most acceptable for inclined and steeply dipping seams. In this case, surface mining of coal pillars is carried out with the deepening longitudinal method, piling the external dumps with high dust emission and occupying significant areas.

To reduce the area of sites occupied by external dumps and dust emissions, as well as the cost of overburden transporting for closed mines coal pillars surface mining, this article proposed a solution based on the continuous lateral method of mining inclined and steeply dipping seams, with the layer-by-layer excavation of rock-and-coal blocks and placement of overburden in the internal dump. Three modifications of this continuous lateral mining method are recommended (for coal seams strata of high and medium thickness, as well as for dispersed seams). All three modifications have small (no more than $2.5 \%$ ) variation in the volume of coal 
and overburden within the quarry field but differ in excavation equipment for coal extraction (dragline or hydraulic backhoe), the width of the working zone, the thickness of the layer, and the height of the dump tier.

The use of the continuous lateral method of coal pillars mining can significantly reduce the land area occupied by the quarry field and the external dump (in 11-13 times), the height of the external dump (in 3 times), dust emission (in 10-13 times, depending on the quarry depth), compared with deepening longitudinal method. Along with this, the replacement of dump trucks with dragline for overburden transporting for continuous lateral mining method allows reducing the cost of overburden transporting in 3.5-5.5 times compared to deepening longitudinal method (depending on the quarry depth).

At the same time, the limitations of the coal pillars mining method presented in the article affect a small part of the closed mines' fields that can be developed in a surface way - mainly of low-grade coal and high tectonic disturbance, as well as with important natural objects located on the ground. Therefore, future research in the field of coal deposits integrated development may well affect the improvement of continuous lateral surface mining method for the extraction of coal from mine pillars, particularly the use of more productive equipment.

\section{References}

Baruya, P. (2012). Losses in the coal supply chain. London. EA Clean Coal Centre, 65 p. DOI: 10.13140/RG.2.2.19769.26727

Bereznyak, M.M., Kalinin, A.V. and, Pronoza, V.G. (1970). A method of calculating the width of the caved rubble in the transportless system of working a series of sloping beds. Soviet Mining, 6(6), pp. 638-643

Changsheng, J. (2012), Surface Coal Mining Methods in China. In: Mining Methods, ed. by T. Onargan. In Tech. Rijeka, pp. 23-30. DOI: 10.5772/35061

Cheskidov, V.I., Norri, V.K. and Sakantsev, G.G. (2014).Diversification of open pit coal mining with draglining. Journal of Mining Science, 50(4), pp. 690-695.

Czaplicki, J.M. (2010). Mining equipment and systems: theory and practice of exploitation and reliability. CRC Press, London, $285 \mathrm{p}$.

Demirel, N. (2011). Effects of the rock mass parameters on the dragline excavation performance. Journal of Mining Science, 47(4), pp. 441-449.

Gvozdkova, T., Markov, S., Demirel, N. And Anyona, S. (2017). Modeling of Three Flat Coal Seams Strata Developing at Open Pit Miming. E3S Web of Conferences, 21, 010242

Harper, D. (1985). The Development of Surface Coal Mining in Indiana. Bloomington, Department of Natural Resources of the State of Indiana, $65 \mathrm{p}$.

Hudeček, V. And Stoniš, M. (2010). Forecast and Prevention of Coal and Gas Outbursts in the Case of Application of a New Mining Method - Drilling of a Coal Pillar. Acta Montanistica Slovaca, 15(2), pp. $102-108$

Hummel, M. (2012). Comparison of existing open coal mining methods in some countries over the world and in Europe. Journal of Mining Science, 48(1), pp.146-153.

Jarvie-Eggart, M.E. (2015). Responsible mining: case studies in managing social and environmental risks in the developed world. Society for Mining, Metallurgy, and Exploration. Littleton, Colorado, 804 p.

Katsubin, A.V. and, Makridin, E.V. (2018).Systematization of the technological schemes of excavator faces at the central Kuzbass open pit mines. Journal of Mining and Geotechnical Engineering, 1, pp. 81-88 doi: 10.26730/2618-7434-2018-1-81-88

Kennedy, B.A. (2009). Surface Mining. 2nd Edition. Littleton, Colorado. Society for Mining, Metallurgy, and Exploration Inc., $1207 \mathrm{p}$.

Kose, H. And Pamukcu, C. Yalcin, E. (2010).Project design of an open pit colliery in Terkidag, Turkey. Acta Montanistica Slovaca, 15:2, pp. 109-120

Kulakov, V.N. (1995). Geomechanical conditions of mining steep coal beds. Journal of Mining Science, 31(2), pp. 136-142.

Kurekhin, E.V. (2015).Substantiation of low-capacity equipment sets for open pit coal mining, considering land use efficiency. Journal of Mining Science, 51, pp. 888-894

Kushwaha, A., Singh, S.K., Tewari, S. and Sinha, A. (2010). Empirical approach for designing of support system in mechanized coal pillar mining. International Journal of Rock Mechanics and Mining Sciences, 47(7), pp.1063-1078 DOI: 10.1016/j.ijrmms.2010.06.001

Kuznetsov, V.I., Mattis, A.R., Tashkinov, A.S., Vasil'ev, E.I. and Zaytsev, G.D. (1997).Efficiency of excavation of overburden rock at quarries with the use of blast-free technology. Journal of Mining Science, 33(5), pp. 471-477. 
Lesin, Y.V., Luk'yanova, S.Y. and Tyulenev, M.A. (2015).Formation of the composition and properties of dumps on the open-pit mines of Kuzbass. IOP Conference Series: Materials Science and Engineering, 91(1), 012093.

Litvin, O., Tyulenev, M., Zhironkin, S. And Prokopenko, S. (2017),Methodology of coal losses calculation at open pit mining for complex geological conditions - review. Acta Montanistica Slovaca, 22(2), pp. 146152.

Lukhele, M.J. (2002).Surface auger mining at Rietspruit Mine Services (Pty) Ltd. Journal of South African Institute of Mining and Metallurgy, 102(2), pp.115-119

Manová, E., Čulková, K., Lukáč, J., Simonidesová, J. And Kudlová, Z. (2018).Position of the chosen industrial companies in connection to the mining. Acta Montanistica Slovaca, 23(2), pp. 132-140

Mishra, P.C. and Mohanty, M.K. (2019).System sequence of surface mining operation. International Journal of Applied Systemic Studies, 8(4), pp. 68-82 DOI: 10.1504/IJASS.2018.103768

Mitra, R. And Saydam, S. (2012). Surface Coal Mining Methods in Australia. In: Mining Methods, ed. by T. Onargan. In Tech. Rijeka, pp. 23-30. DOI: 10.5772/39172

Nazarov, I.V. (2011). Numerical modeling of overburden rehandling with draglines. Journal of Mining Science, 48(1), pp. 55-61.

Oparin, V.N., Cheskidov ,V.I., Bobyl'sky, A.S. and Reznik, A.V. (2012).The sound subsoil management in surface coal mining in terms of the Kansk-Achinsk coal basin. Journal of Mining Science, 48(3), pp. 585594.

Prakash, A., Mallika, V., Murthy, S.R. and Singh, K.B. (2013).Rock excavation using surface miners: an overview of some design and operational aspects. International Journal of Mining Science and Technology, 23(1), pp. 33-40.

Song, Z.-Q., Cui, Z.-D. and Xia, H.-C.(2010).The fundamental theoretical and engineering research on the green safe no coal pillar mining model by mainly using coal gangue backfill. Journal of the China Coal Society, 35(5), pp.705-710

Squillace, M. (1990). The Strip Mining Handbook. Boulder. University of Colorado Press, 124 p.

Stoniš, M. And Hudeček, V. (2009).Mining of coal pillars using the drilling method. Acta Montanistica Slovaca, 14(3), pp. 241-249.

Sun, W., Zhang, Q., Luan Y. and Zhang, X.P. (2018).A study of surface subsidence and coal pillar safety for strip mining in a deep mine. Environmental Earth Sciences, 77, pp.627 DOI:10.1007/s12665-018-7810-y

Tanaino, A.S. and Cheskidov, V.I. (1999). Substantiation of the sequence for opencast mining of a series of flat and inclined strata using the mined-out space for internal dumps. Journal of Mining Science, 35(3), pp. 304-313.

Tatiya, R.R. (2013). Surface and underground excavations: methods, techniques and equipment. CRC Press, London, 904 p.

Tyulenev, M., Litvin, O., Cehlár, M., Zhironkin, S. And Gasanov, M. (2017). Estimation of hydraulic backhoes productivity for overburden removing at Kuzbass open pits. Acta Montanistica Slovaca, 22(3), pp. 296302.

Tyulenev, M., Markov, S., Cehlar, M., Zhironkin, S. And Gasanov, M. (2018). The model of direct dumping technology implementation for open pit coal mining by high benches. Acta Montanistica Slovaca, 23(4), pp. 368-377.

U.S. Congress, Office of Technology Assessment, Western Surface Mine Permitting and Reclamation. (1986). OTA-E-279. Washington, DC. U.S. Government Printing Office, 46 p.

United States Environmental Protection Agency. (2008). Coal Mining Detailed Study. New York. EPA, 153 p.

Writer, S. (2014). Underground v.s. Surface Coal Mines: Is Deep Drilling Worth the Cost? Mining Global, 3:17 pp.1-7

Yang, J.-X., Liu, C.Y. and Yu, B. (2016).Effects of load distribution exerting on coal pillars on the stress and energy distribution of the floor strata. Acta Montanistica Slovaca, 21(2), pp. 102-112.

Yu, Y., Deng, K.Z. and Chen, S.E. (2018).Mine Size Effects on Coal Pillar Stress and Their Application for Partial Extraction. Sustainability, 10, pp.792 DOI: 10.3390/su10030792

Zhaoxue, Z. and Hong, Y. (2010). Application of open-pit and underground mining technology for residual coal of end slopes. Mining Science and Technology, 20(2), pp. 266-270.

Zhengao, Z., Li, M., Kemin, L., Xiaohua, D. and, Shuangshuang, X. (2017).Comparative study of mining methods for reserves beneath end slope in flat surface mines with ultra-thick coal seams. International Journal of Mining Science and Technology, 27, pp. 1065-1071

Zhironkin, V. And Janocko, J. (2019). Revitalization of coal brownfields in solving environmental problems and structural development of Kuzbass economy. E3S Web of Conferences, 134, 02002.

Zi, L.M and Ding, W. (2010).The Application Research on Backfill Mining Technology of Gangue for Coal Pillar Mining in Xingtai Mining Village. Advanced Materials Research, 156-157, pp.225-231 DOI: 10.4028/www.scientific.net/AMR.156-157.225 